\title{
Is diplomacy an Option? \\ Finance Theory and Brexit
}

By Mark Howard ${ }^{1}$

\section{Introduction}

It is almost a platitude to say that under conditions of uncertainty having options confers value. However, why is this so? What is the character of options such that they bestow value upon the bearer? Moreover, what is the substance of the value they bestow? The Oxford English Dictionary defines an option as the "power or liberty of choosing: opportunity or freedom of choice," ${ }^{2}$ which immediately links the notion of optionality to: 1) autonomy, or the power to rule oneself; and 2) a future not yet determined. Understood in this way, the value of an option appears as nothing short of the value of freedom, and therefore invokes a long tradition of Western thought concerning political and economic liberalism. It is at the tangent of these two domains-the political and the economic - that the following discussion considers options and optionality.

In politics, pure optionality is derived from the status of sovereign authority; in economics, from the status of liquidity. It is my intention in what follows to draw out the similarities and parallels between these two statuses through their representative forms: diplomacy, in the case of sovereignty; and finance, in the case of economics. This choice is somewhat inevitable, for neither sovereignty nor liquidity possess substance short of their enaction. It is in the domains of diplomatic intercourse and financial transactions that both are declared and given continuing presence and existence. Each pivots not merely on power or material reality as is commonly assumed, but on collective sentiments of trust and confidence. Without collective ongoing faith in the ability of sovereignty or liquidity to mediate and preserve the possession and/or exchange of socially valued goods, there would be no authority or legitimacy in their essential function. Put simply: they are what they do.

\footnotetext{
${ }^{1}$ Submitted for presentation at the 2020 APSA Virtual Conference

2 "option, n.". OED Online. June 2020. Oxford University Press. https://www-oed-

com.oca.ucsc.edu/view/Entry/132082?rskey=4hzhCp\&result=1\&isAdvanced=false (accessed August 20, 2020).
} 
While in the context of politics and sovereignty the term 'option' bears a similar meaning to its everyday usage-something like "the availability of different choices" - in the world of finance, the term Option (capitalized for distinction) has a precise meaning. It designates a contractually defined derivative asset type that someone can literally possess under the institution of private property. In financial economics, experts ${ }^{3}$ have spent decades developing and packaging Options to minimize the scope and impact of risk taken by investors speculating on financial markets. Their models are highly technical and mathematical in character, which is aptly suited to the quantitative field of Financial Economics. However, many aspects of Options, not least of all their ability to produce liquidity from illiquid assets, are grounded in intertemporal philosophical concepts that are analogous to and, I argue, suitable for application in, qualitative fields of study such as international strategy and diplomacy-two of the forms in which state sovereignty is exercised. In the simplest terms, Options endow their owner rights without obligations, which is also an endowment central to both domestic and international notions of liberty. It is, moreover, the concept of (individual or state) sovereignty that anchors such endowments, and yet the connections between Options in politics and economics have so far been relatively unexplored.

In what follows, I argue that Options theory offers a ready-made set of models and concepts that might be adapted for diplomatic negotiations and strategies in rapidly changing contexts, but that have as yet been under-exploited in the field of international relations and political theory in general. I present my argument in four parts. First, drawing on the work of Elie Ayache, I argue for the primacy of practice over theory in determining future political outcomes for states and sovereign authorities. Through the constant recalibration of options, diplomats, much like traders, have the paradoxical ability to produce possibilities and causes retroactivelyan informally produced feat that with the aid of Options theory might be formalized when it comes to exercising and trading options between sovereign bodies. Second, I develop the parallels between liquidity and sovereignty, and demonstrate the various ways in which unimpeded sovereignty confers options which might be packaged as Options. With recourse to

\footnotetext{
${ }^{3}$ Including not merely financial economists, but also physicists and mathematicians due to the technical complexity involved
} 
forthcoming work by Robert Meister, I connect Finance Theory with Political Theory to produce a set of political strategies that are not as yet commonplace within the domain of international power relations. Third, I introduce and build upon a sub-branch of Options theory known as the 'Real Options' approach, a burgeoning field or practice that applies Options in a more qualitative way than financial economics, but that has so far only been applied to the context of business management and not state politics. Likening the state to a firm, I outline some precedents for Real Options in diplomacy and international strategy, before posing some suggestions for Options strategies in international relations. Finally, I apply some of the concepts and speculative strategies discussed in this paper to the anticipated negotiations and strategic realignments that the United Kingdom is and will be engaging in as the reality of Brexit approaches its denouement amidst a disintegrating Western Liberal Democratic alliance. Although it is unlikely that an Options-based approach will be used in the short time remaining for Brexit, I hope to demonstrate how such an approach might be beneficial in salvaging a set of win-win outcomes from what appears to be a lose-lose situation.

\section{I: Inverted Praxis: The Market for Diplomacy}

The word 'strategy' is borrowed from ancient Greek and denotes the "office or command of a general. ${ }^{4}$ As we know, generals-be it in a battle setting or the more mundane confines of a corporate office--are not typically found in the thick of action but rather orchestrate operations from afar, and normally before the action begins. The general strategizes; he or she fixedly sets the policies and plans in advance. Thereafter, he or she considers them immobile commands handed down for execution by operational managers with limited autonomy for creative maneuver. In terms of international relations, we might think of this as the foreign policy of a sovereign government, which is to be distinguished from the managerial-like role of the diplomat. Whereas the policymaker forms the fixed substance of a sovereign state's strategy towards other states, the diplomat is engaged in "the process of dialogue and negotiation by which states in a

\footnotetext{
4 "strategy, n.". OED Online. June 2020. Oxford University Press. https://www-oedcom.oca.ucsc.edu/view/Entry/191319?rskey=zdhRaY\&result=1\&isAdvanced=false (accessed August 20, 2020).
} 
system conduct their relations and pursue their purposes by means short of war." ${ }^{5}$ Moreover, diplomacy is the method by which these relations are actively managed and adjusted through various skillful means ${ }^{6}$.

One implication we can draw from the distinction between strategists and diplomats is that a significant amount of the historical achievements of international relations are, in fact, due to the work of diplomatic practice and not strategic policy. Even where sovereigns have retained a direct role in negotiation processes, the nature of their involvement has typically forced them to behave more like diplomats than strategists, ${ }^{7}$ suggesting a reversal of the commonplace assumption that strategy is primary to tactical execution. Furthermore, it implies that there is a primacy of practice over theory. Although theory and strategy are necessary and important, they constitute only the starting point from which practice and diplomacy must go beyond.

This is because the modeling activities of theorists and strategists are limited in their ability to account for, or respond to, contingency. Strategies and theories try to model future outcomes of the world as if they were already written, yet the one thing we know about the future is that it will not be identical to the past. Moreover, all leaders are subject to bounded rationality, cognitive limitations, and behavioral biases, compounding the difficulty of interpreting complexity in uncertain situations. ${ }^{8}$ In the context of diplomacy, 'deliberate' strategies will inevitably morph into 'emergent' strategies, where the latter denotes "patterns ... realized despite or the in absence of intentions." 9 Thus, diplomatic practice is revealed to operate somewhere beyond theory and strategy, as both the outcome and input of a strategy in execution.

Kissinger ${ }^{10}$ explains this phenomenon by noting that it is reality rather than policy or strategy that links events together in history. While diplomacy in the present depends on and

\footnotetext{
5 Jozef Bátora *, "Does the European Union Transform the Institution of Diplomacy?," Journal of European Public Policy 12, no. 1 (February 2005): 46, https://doi.org/10.1080/1350176042000311907.Adam Watson, Diplomacy The Dialogue Between States (Florence: Taylor and Francis, 2013), 10.

${ }^{6}$ Ernest Mason Satow, Satow's Guide to Diplomatic Practice, 5th ed (London ; New York: Longman, 1979$), 3$.

${ }^{7}$ Paul Sharp, “Diplomatic Theory of International Relations," n.d., 35.

8 Jeffrey J. Reuer and Tony W. Tong, eds., Real Options Theory, 1st ed, Advances in Strategic Management, 24.2007 (Amsterdam: Elsevier JAl, 2007), 23.

${ }^{9}$ Lawrence Freedman, Strategy: A History (New York: Oxford University Press, 2013), 554.

${ }^{10}$ Henry Kissinger, Diplomacy (New York: Simon and Schuster, 1994), 715-19.
} 
grows from history, it creates the future in medias res through practice and makes its own contribution to the historical continuum. ${ }^{11}$ This problem is revealed by what Nassim Taleb calls 'The Black Swan,' Elie Ayache calls 'The Blank Swan,' and Donald Rumsfeld colorfully called "unknown unknowns"12 - each being, quite simply, events so improbable or impossible that they remain inevitably unaccounted for in the list of scenarios a strategist or theorist will use as inputs to their plan or model. Such events can be both positively and negatively impactful, sometimes to a great degree, which is why in fields such as financial economics, hedging strategies-preemptive compensating transactions that can protect or profit from unexpected events-have become so commonplace. Strategy and diplomacy share with finance interest in producing beneficial outcomes in an uncertain world, profiting from what are known as 'contingent claims' in the financial world. So why has no-one yet tried to apply the methods of the latter to the former?

If we are to make this connection, then it seems practical to analogize 'the market' in finance to 'the international' in international relations. In each case, the object in question constitutes a space in which self-interested parties engage in transactions, sometimes for the mutual benefit of the parties involved, and invariably for the continued existence of the environment itself. Ayache ${ }^{13}$ speaks of the market as 'the medium of contingency,' which denotes not merely the space in which contingent events occur, but also the space in which contingent events are written. I would argue that the same is true of the international.

To understand how this works, we must first concede the indisputable fact that contingent events do occur, despite not being accounted for in prior evaluations of the system. ${ }^{14}$ When such an event occurs, it cannot be ignored but must be responded to by practitioners in the field. They, by their practical intervention and newly-acquired knowledge, recalibrate (re-

\footnotetext{
${ }^{11}$ Cf. Berridge on Kissinger. G. R. Berridge, Diplomacy (London: Palgrave Macmillan UK, 2015), 184, https://doi.org/10.1057/9781137445520.

12 Nassim Nicholas Taleb, The Black Swan: The Impact of the Highly Improbable (New York: Random House, 2010); Elie Ayache, "In the Middle of the Event," in The Medium of Contingency, ed. Robin Mackay, Urbanomic (MIT Press, 2011); Ian Bremmer and Preston Keat, The Fat Tail: The Power of Political Knowledge in an Uncertain World (Oxford ; New York: Oxford University Press, 2010), 17.

${ }^{13}$ Ayache, "In the Middle of the Event."

${ }^{14}$ In terms of international relations, such prior evaluations would be constituted by the precedents of history; in financial economics these evaluations are constituted by pricing models
} 
write) the strategic model's assumptions before going about their business until the next contingent event occurs. For Ayache, the philosophical implications are profound: what is being written are literally 'states of the world'; when a trader/diplomat responds to market/international contingency, they are acting in a residuum above or below probability, outside of time and chronology, and directly in the middle of the event. ${ }^{15}$ Like traders, diplomats act in the international/market based on contingent events/claims, thus creating the future and shaping the world through precisely the kind of activity we associate with statecraft. Diplomacy, on this account, becomes both the carrier and product of the international system. ${ }^{16}$

One conclusion to be drawn from the preceding discussion is that future benefits, for states or any other value-seeking actors, will be decided not purely in the realm of strategic planning, but also in the medium of diplomatic contingency. As such, there is a kind of dialectical relation between a strategic-theoretical position that looks to the past, and a diplomatic-practical position that looks to the future. Without both in constant interaction, history cannot proceed, and future value cannot be realized or captured with any certainty. This phenomenon is what Karl Marx in Capital ${ }^{17}$ refers to as 'the realization problem,' the inconvenience that investments made in the present will not realize their value until some-time in the future. By that time, contingent events may have intervened. This is the problem that gave rise to institution of finance, and while it is commonplace to think of the finance as a relatively new phenomenon, as merely the most recent evolution of capitalism, financial instruments generally associated with period following Nixon's abandonment of the gold standard in 1971 can be found in texts going back to Antiquity. ${ }^{18}$ Additionally, a growing community of scholars today also argue that financial relations precede economic relations and are the foundation of social order. ${ }^{19}$

\footnotetext{
${ }^{15}$ Ayache, "In the Middle of the Event," 23, 27.

${ }^{16}$ Bátora *, "Does the European Union Transform the Institution of Diplomacy?," 46; Keith Hamilton and Richard Langhorne, The Practice of Diplomacy: Its Evolution, Theory, and Administration, 2nd ed (London ; New York: Routledge, 2011), 264.

${ }^{17}$ Karl Marx, Capital: A Critique of Political Economy: Volume One, trans. Ben Fowkes (Penguin Books, 1976).

${ }^{18}$ Aristotle, in Book I of The Politics tells the tale of Thales of Miletus, who predicted (apparently by the use of moon cycles) that the following year's olive harvest would be bountiful, and therefore paid a small amount of money to have exclusive rights to the olive presses during next year's harvest. This makes him perhaps the first recorded options trader in history.

${ }^{19}$ Cf. for instance David Graeber, Debt: The First 5000 Years (Brooklyn, NY: Melville House, n.d.); Michel Aglietta, Money: 5,000 Years of Debt and Power (London ; New York: Verso, 2018).
} 
Recognizing the importance of finance for fundamental economic interactions gives its methods and insights a more prominent role in considerations of matters from other domains such as international politics. Because finance is so-often erroneously seen as a mere ancillary to international economics, the reason for its importance is missed: finance is about the renewal and growth of value; or, even more profoundly, finance is about bringing the future into the present ${ }^{20}$. It is about recognizing how many risks in the past were unexpected before they were realized and, therefore, that 'the unexpected' will undoubtedly occur in the future. Once this is understood, action may be taken to minimize the impact of those risks being realized. In political risk analysis, this practice is generally managed through 'risk mitigation. ${ }^{21}$ However, in finance, something different happens-instead of merely attempting to minimize the impact of a risk realized, financial practitioners actively try to profit from risks realized through so-called hedging strategies employing similar tools-Options-to those used by Thales in ancient Greece. Kissinger famously said that "politics is the art of the possible," and that "those who grab for everything ... in the end may lose all." His point was that the diplomat who always seeks decisive victories over quiet and humble gains is 'mortgaging the future' of his state 22 and ought, therefore, to be discouraged. However, a mortgage is a fixed financial arrangement that places liability on the borrower, and all but locks them into the transaction. Sophisticated investors today reduce their liability and avoid being locked into future unprofitable transactions through financial instruments known as Options-might Kissinger's wisdom be reversed? Might we say that diplomacy can, in fact, seek decisive victories, provided it 'Options the future' instead of mortgaging it?

To make the connection between fields as diverse as finance and international politics, we must perform a translation of terms, much as I did with 'market' and 'international.' Fortunately, many technical terms in finance have colloquial meanings already found in politics and everyday life. Value and price are two such examples. Value is typically understood as a

\footnotetext{
${ }^{20}$ Aglietta, Money, 13.

${ }^{21}$ Bremmer and Keat, The Fat Tail, 14.

${ }^{22}$ T.G. Otte, "Kissinger," in Diplomatic Theory from Machiavelli to Kissinger (Wiltshire, Great Britain: Palgrave, 2001), 198.
} 
relation of equivalence and is closely related to the term 'worth. ${ }^{23}$ Finance textbooks tend to proceed without defining value, as if it is a term so fundamental to our language that it needs no further explanation. However, thinkers going back to Aristotle ${ }^{24}$ have distinguished between at least two types of value: 1) use value, the qualitative dimension of worth that something possesses, so defined by its utility; and 2) exchange value, the quantitative dimension of worth that something has, so defined by the amount required to obtain a specific amount of something else. In terms of international politics, we might, for example, consider the use value of a certain intake of refugees in terms of moral standing in the international environment. In contrast, we might place an exchange value on that in terms of the amount of aid provided to the source (or any other) country-i.e., more refugees taken, less aid given.

In distinction to value, price has a fairly technical meaning in finance and economics and is closely related to the market's operations. Economics 101, for instance, will teach you that price is determined (under perfect competition) through the formation of an equilibrium balance between supply and demand in a market setting. Therefore, price is merely an indicator based on the market and is not necessarily tied in any strict way to value. This has implications for international relations; exchange-be it of goods, people, information, or services-seems to be central to diplomatic relations, ${ }^{25}$ but price does not appear to have the same necessary place. Price, understood in terms of international politics, evokes something closer to the meaning of 'cost' - something sacrificed or surrendered, whether in return for some benefit or not. While one may wish to quantify, in monetary terms, the price of an exchange of people or information, in terms of international relations, monetary valuations do not tell the full story.

Nevertheless, diplomacy is a practice involving continuous trading and adjustment, ${ }^{26}$ just as in the way a market operates to produce price. In Ayache's theory of the medium of contingency, the market pivot between the past and future produces price, which in our analogy constitutes the pivot between strategy-theory and diplomacy-practice. We can think of this as

\footnotetext{
${ }^{23}$ Cf. "value, n." OED Online, Oxford University Press, June 2020, www.oed.com/view/Entry/221253. Accessed 20 August 2020.

${ }^{24} \mathrm{Cf}$. The Politics, Book I.

${ }^{25}$ Christer Jönsson and Martin Hall, Essence of Diplomacy (London: Palgrave Macmillan UK, 2005), 26, https://doi.org/10.1057/9780230511040.

${ }^{26}$ Watson, Diplomacy The Dialogue Between States, 51-54.
} 
follows: any strategy-theory makes its plan according to a cost-benefit analysis of proposed action. For instance, entering into a visa-exchange program comes with both costs and benefitsdesirable residents may be lost just as others are gained. However, it is in the field of diplomacypractice that real-time adjustments to such a program might be needed to take advantage of contingent events, such as large corporate employers moving office locations across borders, or newly published university rankings making specific destinations more or less desirable to incoming and outgoing persons. In diplomacy, as in finance, it is the exchange itself that disrupts value and price; it is exchange that shapes the future world in an appealing or unappealing form.

\section{II: Liquid Nation: Sovereign Optionality}

In the previous section, diplomacy was defined in practical terms as dialogue and negotiation between states. However, the word itself has its origins in the Greek diploma, which is formed by the prefix diplo-, meaning 'double', and the suffix -oma, indicating the result of verbal action. Therefore, diploma, which gives us diplomacy, has its origins in the meaning 'to double', which is typically understood to refer to the doubling of a piece of paper (a message from the sovereign or authority, or certificate conferred by an institution), while also referring to the doubling of authority in the document and (potentially) its bearer. In this context, we should understand a diplomat as the designated 'double' of the sovereign authority for which he or she represents. In turn, the diplomat has the derivative sovereign authority to negotiate and act on behalf of the sovereign state in relation with other sovereign bodies. Diplomacy is an institution responding to the "common problem of living separately and wanting to do so, while having to conduct relations with others. ${ }^{27}$ In this, it is deeply implicated in the institution of sovereignty.

In this section, I want to connect the concept of sovereignty in international relations to liquidity in finance. I draw this connection from the (forthcoming) work of Robert Meister:

"[L]iquidity is the abstract form of absolute power specific to globalized financial capital-the normative and empirical ground of its existence-in the same way

\footnotetext{
27 Jönsson and Hall, Essence of Diplomacy, 26.
} 
that sovereignty was the abstract form of absolute power specific to the national development of capitalist modes of production."28

Liquidity in finance refers to the quality of being easily exchangeable. A liquid asset can be quickly and easily transferred into other liquid assets, the most liquid of all assets being cash, because cash is pure exchange value. ${ }^{29}$ Illiquid assets such as real estate, on the other hand, can be hard to sell quickly and, if sold quickly, may induce a substantial price discount compared to an unrushed sale situation. ${ }^{30}$ John Maynard Keynes originally noted that the quality of liquidity demands its own premium (or value proposition), highlighting that it offers a utility unavailable to illiquid assets: optionality. Put simply, any asset that is not money has to be exchanged for cash to have the option of using it to acquire another asset. ${ }^{31}$ Liquidity thus becomes desirable for its ability to mediates value in other forms.

I contend that sovereignty has the same effect in the international sphere that liquidity has in the market sphere: sovereignty confers optionality. In Michel Aglietta's account of the origins of money, he argues that the unanimous convention formed around a particular asset such that it becomes the money asset (e.g., gold) is a product of political contestation. Only through continued demonstrations of authority prevailing from this contest is the asset bestowed its quality of pure liquidity. ${ }^{32}$ This claim is highly analogous to the concept of sovereignty, which is, in both its Westphalian origins and the in case of newly formed states (e.g. South Sudan), also a product of political contestation. Moreover, it is only through continued demonstrations of the authority prevailing from this contest that a state is bestowed its quality of pure sovereignty-that is, only if a state is able to sustain its internal sovereignty can it hope to maintain its external sovereignty among other sovereign states.

\footnotetext{
${ }^{28}$ Robert Meister, Justice Is an Option: A Democratic Theory of Finance for the Twenty-First Century (University of Chicago Press, 2021), 16.

${ }^{29}$ To understand this, consider, as per the discussion above, that the use value of money cash is its exchange value. Thus money as cash is nothing but exchange value.

${ }^{30}$ Zvi Bodie, Alex Kane, and Alan J. Marcus, Essentials of Investments, Tenth edition (New York: McGraw-Hill Education, 2017), 20.

${ }^{31}$ Meister, Justice Is an Option, 11.

32 Meister, 18; Aglietta, Money.
} 
Returning to finance, one of the most profitable innovations in modern finance has been the development of an asset class known as derivatives. Derivatives are so named because they derive their value from other underlying assets. The core benefit that such instruments provide is the seemingly magical ability to produce highly liquid assets from relatively illiquid assets. Consider the example of Thales once more. Had he simply purchased the olive presses in order to profit from the predicted harvest, he would have become the owner of a relatively illiquid asset, something that he might not be easily able to convert into cash without a loss. After all, who would be willing to quickly buy olive presses when the crops' realization was as yet uncertain and may not produce anything at all. However, by purchasing the Option to use the olive presses only, Thales obtained a relatively liquid asset that could easily be transferred to another person as the right, but not the obligation, to profit from next year's harvest. If the harvest was good (as it was), then the option could be exercised, and the crop pressed at a bargain price with exclusive rights. If it was bad, as was a distinct possibility, then the option's owner could walk away having only lost a small amount (the fractional price of the option compared to the full price of the olive presses). Consider, though, how much more valuable the option that Thales bought would be after the harvest compared to before the harvest; the price would be much higher because of the profit that could be harvested (literally) from it. Derivatives, therefore, have derived liquidity, which produces derived optionality.

In terms of diplomacy, we can now see how it is that diplomats, as derivative sovereigns, can produce value through the exercise of pure sovereignty. Sovereignty confers optionality in that it bears ultimate authority over the state's operations and the decision to exchange valued goods. ${ }^{33}$ However, this optionality can be severely limited in the advent of contingent events, particularly when the sovereign's strategic plans or policy have not accounted for that contingency. In such a situation, their optionality (sovereign authority) is limited by the situation. However, the ability of diplomats to act in the medium of contingency-in the middle of the event-as derivative sovereigns, re-instigates that optionality. In the process of action and negotiation, the diplomat, thinking on his or her feet and responding with agility (though within

\footnotetext{
${ }^{33}$ Goods understood here in the broadest terms possible. Note that sovereignty also confers the option of acquiring or relinquishing goods without exchange-sometimes by any means necessary, including force.
} 
boundaries) to the contingent event, can mediate the exchange of heterogeneous state goods through the homogenous medium of derived sovereignty. ${ }^{3435}$ Though this may sound fanciful, it is, in fact, much like the principle of linkage practiced by diplomats such as Henry Kissinger during the Cold War, whereby ostensibly discrete policy issues were packed into complex arrangements intended to produce core valued outcomes. ${ }^{36}$

Conversely, it stands to reason that if sovereignty confers optionality, then any limitation to sovereignty will deny or limit that optionality. Optionality is liberty, and liberty is optionality. Thus, under the arrangement of colonial or pseudo-colonial relations, such as with the British lease of Hong Kong from 1898 to 1997, it becomes easy to see how the value of sovereignty might exceed the value of limited or curtailed sovereignty. Sovereignty implies absolute optionality that cannot be derived from other state arrangements. The same phenomenon becomes evident to a lesser degree in international institutional frameworks, such as the World Trade Organization (WTO) or the United Nations, whereby certain limitations are imposed upon member states' unfettered optionality. On the flip-side, of course, we should not ignore the potential benefits that come from these types of institutional frameworks; not partaking in international institutions in order to preserve state sovereignty could, for example, be likened to a premium in financial economics - it would be, as such, the price for isolationism. Moreover, just as in the financial world, it would be a premium that some can afford, and others cannot (thereby implying that merely having the option of not partaking in an international institution is itself an asset). ${ }^{37}$

If submitting to the international institutional order thus implies an investment of sovereignty, it is because such submission exposes the sovereign state to the vicissitudes or strictures of externally accountable (if accountable at all) bureaucracies. But as noted above such

\footnotetext{
${ }^{34}$ Heterogenous goods here refers to an exchange of unlike goods, such as the issuance of sovereign debt in return for Foreign Direct Investment (FDI) opportunities. The homogenous medium referred to is the common primary institution of sovereignty that all states partake in as members of the international system.

35 This is, I should note, analogous to the way in which financial engineering acts as a technology for taking heterogenous - often incommensurable-assets and datasets and artificially sets them on a value par with one another. Cf. Meister, Justice Is an Option, 275.

${ }^{36}$ In this case it was to have strategic and tactical control over the ideological battle between Western Capitalism and Soviet Communism Otte, "Kissinger," 195.

${ }^{37}$ Consider the US refusal to become party to the International Criminal Court, a privilege that African countries, for instance, do not have and that has seen them disproportionately represented in cases brought to that court relating to crimes against humanity.
} 
arrangements are not intended to be entered into to the detriment of sovereign states, but rather for their benefit. If we consider that financial Options pricing begins with the idea that by purchasing an asset for a fixed amount, one gains exposure to future movements in that assets price-gaining when if rises and losing when it falls ${ }^{38}$ - then we can understand how giving up a portion of liquidity (e.g. money) or sovereignty (e.g. tariff limits) could mean gaining the opportunity to profit from future movements that might generate more value than what was given up.

With this understanding in mind, we are now able to assess the applicability of particular subclasses of Options in terms of international relations-namely, so-called Puts and Calls. Both types of Option may be either sold or purchased. Purchasing such Options in each case imparts right without obligations over a fixed time period. ${ }^{39}$ In the case of a Put, it is the right to sell an asset; in the case of a Call it is the right to buy. Selling Options reverses the relation by placing the obligation on the seller: the obligation to buy an asset in the case of a Put, and the obligation to sell in the case of a Call. Each party in an Option trade is making a wager based on the futurethose who would buy a Call or sell a Put are predicting that the asset or good will increase in value over the period in question, while those who sell a Call or buy a Put anticipate a decrease in value over the same period. ${ }^{40}$ These two positions, in financial terms, are known as bullish and bearish strategies: a bull is optimistic about a rise in the value of an underlying asset (and therefore buys Calls or sells Puts), while the bear is pessimistic (and therefore buys Puts and sells Calls). Because Option values depend on the value of an underlying asset or good, an Option

\footnotetext{
${ }^{38}$ Meister, Justice Is an Option, 22.

${ }^{39} \mathrm{Cf}$. Marcia L. Stigum, Anthony Crescenzi, and Marcia L. Stigum, Stigum's Money Market, 4th ed (New York: McGraw-Hill, 2007), 56-57, 793.

${ }^{40}$ In the case of Thales, what can see that he purchased a Call option on the presses, based on his scientific analysis that a good olive harvest was coming. The owner of the presses would, however, have seen the opposite situation and presumed that a bad harvest was coming-hoping to make some profit (because the presses would not be needed at all in the event of a bad harvest) the owner therefore sold a Call option. Remember, the owner would still receive, in addition to the Option premium, the pre-arranged fee for the leasing of the presses. The Option is not the asset itself, but rather an option (right but not obligation) to lease the asset for a pre-arranged fee. Had Thales already leased the presses and foreseen a bad harvest, he may have sought a Put option -the right but not obligation to sell the lease to someone else, but in this case he would be relying on someone else to wager that the lease would be worth something in future, and to therefore sell the Put. This is the same relation seen in standard car or home insurance contracts-your insurance premium is the cost incurred for the insurance company to take on the obligation to 'buy' your asset, within a fixed time period, should your assets price drop (e.g. should you write-off your car in an accident).
} 
investment may be understood as a substitute for the direct purchase of that asset or good. ${ }^{41}$ Options do not replace traditional investments, but rather supplement them as a "side-bet between two investors". ${ }^{42}$

While some imagination is involved, it is clear that there are situations in international relations that invoke time-limited agreements, make forward-thinking investments of resources, or produce legal arrangements bestowing obligations or rights. For instance, Treaties impose obligatory or binding conditions, while Acts do the same with the addition of legal rights, and other instruments in the international sphere such as the Atlantic Charter of 1941 impose no obligations whatsoever. ${ }^{43}$ In the case of treaties, it is clear that they continue to have an operative effect for as long as they are deemed valuable to the parties involved, for while many treaties provide that they be in force for a specified period of time, that does not necessarily preclude the option of abandonment by its signatories. Alliances and collective security arrangements also impose obligations and rights. Though they may not be fully binding in an international environment of anarchy, they have historically been adhered to because the costs of abandoning such arrangements were deemed more costly or risky than fulfilling one's obligations. ${ }^{44}$

As already noted, entering into such arrangements often involves a cost-a premium, if you will-related to the loss of optionality that the agreement's obligations impose. Parties entering into such agreements generally do so to gain more in the future than they lose in the present. This is not always the case, however, because of the role of power in international relations. Unlike in a domestic environment, whereby agreements are enforceable by law through the backing of a sovereign government, in international relations, to put it bluntly, 'might makes right' when it is convenient to do so. In this sense, power is the ability to exercise sovereignty separate from the economic reality of resource endowments or size. Power is the ability to extend one's sovereign optionality into the future in ways analogous to how finance does the same for liquidity; finance is to the economy what power is to politics. And drawing on this line of argument, it is worth pointing out that just as in the world of finance, there are means

\footnotetext{
${ }^{41}$ Bodie, Kane, and Marcus, Essentials of Investments, 492.

42 Stigum, Crescenzi, and Stigum, Stigum's Money Market, 801.

${ }^{43}$ Cf. Satow, Satow's Guide to Diplomatic Practice, 238, 258.

${ }^{44}$ Kissinger, Diplomacy, 608.
} 
of last resort to preserve liquidity, so too in international relations there are means of last resort to preserve sovereignty: war. Just as the condition of illiquidity or socialist revolution is unthinkable in terms of financial order, ${ }^{45}$ so too is the abdication of sovereignty or submission to political revolution in terms of sovereign statehood. Of course, this is not the only way to assert one's power. In modernity, having a comparative (or competitive) economic advantage has arguably been far more advantageous than war. Hence why hegemonic powers such as the United States today, and the British Empire before it, have been evangelists for liberalized economic relations around the globe: the cost of entering into such relations for advantaged and more powerful states are minimal compared to the gains. To paraphrase Aristotle (and later Thomas Jefferson): there is nothing so unequal as the equal treatment of unequals. ${ }^{46}$

\section{III: The Future Will Not Be Like The Past: Real Options for Diplomacy}

Up to this point, I have been speaking of Options in relatively generalized terms for ease of exposition and translation. However, certain financial technical aspects need to be understood to fully appreciate Options possibilities and limitations. Much of this is revealed by the BlackScholes Options pricing formula developed in $1973 .{ }^{47}$ This formula became arguably the most important catalyst to the progressive financialization of capitalism that has been occurring over the past five decades. The purpose of the formula is to calculate the appropriate price for an Option (Put or Call) based on five inputs: 1) the Option strike price (the price that the Option gives the right for an actor to buy or sell at in the future); 2) Time to Maturity (the duration that the Option is in effect and the time-bounded limits in which it may be executed) ${ }^{48}$; 3) the price of the underlying asset (whose value movement is being wagered upon); 4) the volatility of the underlying asset (measured by the magnitude, but not the frequency, of fluctuations in value); and 5) the risk-free rate of interest (which measures how much interest might have been gained

\footnotetext{
${ }^{45}$ Meister, Justice Is an Option, 26.

${ }^{46}$ Cf. Aristotle, Book V, Nicomachean Ethics

${ }^{47}$ Fischer Black and Myron Scholes, "The Pricing of Options and Corporate Liabilities," The Journal of Political Economy 81, no. 3 (1973): 637-54.

48 There are actually two types of Options distinguished by the time to maturity factor: European-style Options, whereby the Option may only be exercised on a fixed date in the future, and American-style Options which may be exercised on any date within a fixed range. The Black-Scholes formula was designed for the former.
} 
on the liquidity used to purchase the Option had it been invested over the same period in a riskfree bond). ${ }^{49}$

One of the most interesting aspects of the Black-Scholes formula is the phenomenon of 'implied volatility.' Because price is both an input and an output of market interactions, the formula, which (to simplify greatly) puts price on one side of the equation and the five inputs on the other, may be rearranged so that volatility sits on one side of the equation and price becomes one of the inputs. ${ }^{50}$ This causal reversal is precisely what is at stake in Ayache's argument about the medium of contingency: because price is the fluctuating symbol of real-time interactions in a market (or international) environment, it can theoretically tell us something about the futurehow volatile and unstable the future will be. Of course, we could estimate implied volatility by measurement of past volatility, but as has already been noted several times: the one thing we know is that the future will not be like the past.

The obvious problem with applying quantified formalizations such as Black-Scholes to matters of international relations is that many aspects of strategic and diplomatic activity are not quantifiable, but instead possess a qualitative character. Furthermore, it is not always the case that a sovereign asset or good-be it intelligence sharing, low tariffs, sanctuary, or whatevermay be transferable in the way that an economic asset is. Fortunately, a more recent branch of Options theory, known as the 'Real Options' approach, was developed to address this problem. ${ }^{51}$ While still aspiring to the possibility of formalizing Option valuations and offering rigorous methods, Real Options allow for more qualitative aspects of future planning and hedging. It also considers the fact that sometimes the underlying assets involved in Options are not transferable to others. ${ }^{52}$ Furthermore, Real Option values are generally influenced by managerial actions, which in our analogous case would apply to diplomatic practice.

\footnotetext{
${ }^{49}$ Stigum, Crescenzi, and Stigum, Stigum's Money Market, 817.

50 Stigum, Crescenzi, and Stigum, 818; Jonathan B. Berk and Peter M. DeMarzo, Corporate Finance, 4th edition (Boston: Pearson, 2017), 804; Ayache, "In the Middle of the Event," 27.

51 Though it should be noted that the Real Options approach is still a young subdiscipline and the breadth of its applications is still a topic for debate. I see this paper as in some ways contributing to that debate.

52 Though it should be noted that Real Options comes in two methodological forms: Real Options Reasoning, which is a more qualitative exercise; and Real Options Modeling, which attempts to quantify and formalize Real Options where feasible. Cf. Jing Li, "Real Options Theory and International Strategy," in Real Options in Theory and Practice, ed. Jeffrey J. Reuer and Tony W. Tong, Financial Management Association Survey and Synthesis Series (Oxford ; New York: Oxford University Press, 2009), 71.
} 
Real Options focus on projects, which are risk-prone investments in activities offering a value proposition over a proposed timeframe. They include categories such as the option to enter, expand, abandon, defer, switch, or downsize investments, ${ }^{53}$ and within the context of a project or venture, three qualitative dimensions are driving the value of Real Options: 1) changes to the Net Present Value (NPV) of the venture, NPV being calculated by subtracting invested value from projected future value streams; 2 ) the length of the timeframe that the Real Options is valid or available, which allows decision makers more or less time to learn more about the future volatility positively or negatively impact the venture's NPV; 3 ) changes to the risk-free interest rate of the current and proposed future investment into the venture, which amounts to value gained or lost by sticking with the investment and not pursuing other (or no) opportunities. ${ }^{54}$

Comparing these qualitative dimensions of Real Options to international relations depends on the state's thinking as similar to a firm. Just as a firm is understood as a collection of projects, a sovereign state might be understood as a collection of firms and projects. To maximize its future opportunities, a firm must engage in activities such as marketing, accounting, economics, strategy, operations, and organizational behavior adjustments, ${ }^{55}$ in much the same that state governments run campaigns, have fiscal responsibilities, manage the economy, strategize for the future, and command an executive function. Just as firms have to think about their creditworthiness in order to access credit for growth, so too do states. ${ }^{56}$ In fact, they are assessed by the same international credit ratings agencies-organizations such as Moody's or Standard and Poor. States and firms benefit from, and seek to protect, outputs from research and development (R\&D) such as technological innovation and intellectual property, in much the same way. ${ }^{57}$ Also, states generally have multi- or trans-national operations in the way that multiand trans-national corporations (MNCs, TNCs) do. Indeed, it is through Real Options that

\footnotetext{
53 Berk and DeMarzo, Corporate Finance, 825.

${ }^{54} \mathrm{Li}$, "Real Options Theory and International Strategy," 73.

55 Berk and DeMarzo, Corporate Finance, 94.

${ }^{56}$ Meister, Justice Is an Option, 153.

57 Tailan Chi and Edward Levitas, "An Examination of Options Embedded in a Firm's Patents: The Value of Dispersion in Citations," in Real Options in Theory and Practice, ed. Jeffrey J. Reuer and Tony W. Tong, Financial Management Association Survey and Synthesis Series (Oxford ; New York: Oxford University Press, 2009 ), 406.
} 
geographical flexibility and operational agility is exploited by such firms, ${ }^{58}$ in much the way that sovereign states engage in international economic relations.

The purpose or value in employing Real Options is the same for a firm as it is for a state: parameterizing sources of uncertainty and attaching values to the various options embedded in a firm or state's strategic vision and future goals. ${ }^{59}$ A Real Option, much like a financial Option, gives the possessor of that Option the right, but not the obligation, to take certain actions in the future at a certain cost. Real Options are about preparing for contingencies and providing greater room for maneuverability and decision making in the midst of unfolding events. In terms of our argument, having Real Options increases the opportunity for diplomatic practice to harvest value in the medium of contingency under volatile and uncertain conditions. Possessing pre-arranged Options, as rights without obligations, offers greater flexibility than pure strategy for profiting from or avoiding the impact of unknown unknowns. Just as in the financial world, having the time and right to choose confers value. ${ }^{60}$ However, the catch is that when exogenous and endogenous uncertainty or volatility increases, governance structures founded on strict control over specific assets or goods can become an obstacle, ${ }^{61}$ and this is precisely the kind of governance structure we typically associate with the governments of sovereign states. To engage with Real Options will require sovereign bodies to relinquish some of the control it has over operations and diplomatic practice to benefit from the flexibility so enabled. By emphasizing "dynamic efficiency gains, downside risk reduction, and the [state's] ability to seize upside opportunities over time by shifting value chain activities across borders in response to different uncertainties,"62 Real Options help eliminate or manage risk and offer a supplementary value proposition to sovereign states' strategic-diplomatic arsenal.

To consider what this might look like in terms of international statecraft, let us consider a few examples. First, a joint-venture (JV) employing Real Options in the corporate space closely resembles the concept of an alliance or collective security arrangement in international relations. By investing in a JV/alliance, a firm or state can potentially limit the upfront downside costs-be

\footnotetext{
${ }^{58}$ Reuer and Tong, Real Options Theory, 7.

${ }^{59}$ Reuer and Tong, 19.

${ }^{60}$ Meister, Justice Is an Option, 154.

${ }^{61} \mathrm{Li}$, "Real Options Theory and International Strategy," 91.

${ }^{62}$ Reuer and Tong, Real Options Theory, 10.
} 
they diminished liquidity or diminished sovereignty - while positioning itself to benefit from new opportunities and at the same time to gain protection depending on how future conditions unfold. ${ }^{63}$ Another example is the concept of 'modus vivendi,' the title given to a provisional or temporary agreement that is made with the intention of being replaced at some later date. ${ }^{64}$ Satow offers by way of illustration, the "Exchange of Notes of 13 November 1973, constituting an interim Agreement in the Fisheries Dispute between the United Kingdom Government and the Icelandic Government." 65 The agreement related to fisheries in a disputed area and offered a fixed-term (two year) access arrangement, yet the effects of Iceland exercising its options in this agreement are having repercussions even today in the context of Brexit negotiations over access to British fisheries (to be discussed in the next section). A third example could be the abandonment clauses that are generally included (explicitly or implicitly) in international treaties and legal documents-such clauses resemble the 'Option to abandon' specified by Real Options theory, but also allow for the Options to expand that works on the flip-side ${ }^{66}$. The trick, of course, with all of these arrangements, is to not simply engage in Real Options practice according to deliberate strategy, but to shape the environment such that the domain of interaction-the international, the market-itself allows for emergent strategies that can deliver optionality and benefits. That is so that the environment itself imposes a pattern of decision. ${ }^{67}$ This is precisely the kind of activity that the US engaged in through the Bretton Woods system by encouraging and guiding the formation of international institutions that would further its own sovereign aims. It is arguably exactly the same process that we are seeing today in China's Belt and Road Initiative $(B R I){ }^{68}$

The true value of Options is not to be found simply in having them, however, but in the ways that they are combined to become effective. In finance, such combinations are referred to as 'hedging strategies.' Investing in an asset or good and then further investing in a Put Option

\footnotetext{
${ }^{63}$ Reuer and Tong, 8.

${ }^{64}$ Satow, Satow's Guide to Diplomatic Practice, 262.

65 ibid.

${ }^{66}$ Real Options theory also speaks of an 'option to reduce' investment. However, in legal terms this would normally involve a renegotiation of the treaty and/or legal arrangement, as has been happening recently with the renegotiation of the NAFTA agreement under the new so-called USMCA schedule.

${ }^{67}$ Freedman, Strategy, 554-55.

${ }^{68}$ Bruno Maçães, Belt and Road: A Chinese World Order (London: Hurst \& Company, 2018), 19.
} 
is, for instance, called a 'Protective Put,' and functions in almost the same way as a car insurance policy. Or, consider the combination of investing in an asset and at the same time investing in a Call Option (a 'Covered Call'). In this case the investing agent is wagering on profiting from the premiums collection on the Options, presuming that the underlying asset or good will likely not increase in value by any great amount. If it does and must then be sold at the strike price, then the loss of potential value beyond the strike price will have been compensated for by the premiums collected. Perhaps one of the most common and apparent strategies is the so-called 'Straddle,' in which both a Put and a Call are purchased for the same asset or good. In this case, there is a profit to be made whether the underlying value goes up or down. The only way a loss could be realized is if the asset does not move beyond the strike price of either Option. ${ }^{69}$ Note in this last example, though, that perhaps the most effective way to execute such a strategy is by purchasing the Options, but not the underlying asset or good. By doing this, there is only minimal upfront exposure to future uncertainty and volatility. The Put, in this instance, becomes not a vehicle for protection of an asset or good you already possess, but rather it becomes a vehicle of value in itself because it can be passed on, for a cost, to another agent that either wants to purchase the underlying asset or good at a more reasonable price than the market is offering, or already possesses the asset or good and now wants to get rid of it with minimal loss.

In terms of international relations, it is this last point that is perhaps most underexploited and would constitute the most radical departure from traditional relations of exchange. Being able to exchange Options, rather than actual goods, would be an innovation with severe risks, and potential win-win benefits. Let us consider the hypothetical example of a sovereign state wanting to exchange Options relating to military technology. In this scenario a smaller, peaceful, developing nation might want to purchase a Call option to purchase the military technology (or at least $R \& D$ related to it) without actually purchasing the technology. They might do this expecting conflict to break out in some other region, with the hope that they could pass on the option to a state engaged in that conflict for some exchanged value item (not necessarily cash) exceeding the initial cost of the Option. The reverse might occur for a nation that was previously engaged in conflict, but now no longer is and therefore no longer wants a military technology

\footnotetext{
${ }^{69}$ Berk and DeMarzo, Corporate Finance, 494-99.
} 
contract. In this case they might wish to purchase a Put to pass it on. The benefits to be gained in this scenario are significant, however the complexities and geopolitical ramifications are immense. What if the military technology provider does not want the technology going to a particular international actor? All sorts of preconditions and limitations would need to be in place for this to work, and the danger is that they may diminish the value of the Option in the first place.

This scenario raises the difficult question of whether a shift towards international strategic and diplomatic Options us feasible or even desirable. However, if difficulties were absolute impediments to change, then innovation would be a rare occurrence, and the history of diplomacy suggests innovations have and will continue to occur. ${ }^{70}$ Bátora argues that these innovations occur in two ways: as changes in diplomacy, and changes of diplomacy. While the former refers to the qualitative content-related changes, the latter refers to structural change and occurs in four kinds of ways: isomorphism, which means closer and more widespread adherence to a common existing standard; fragmentation, which involves a pluralization of standards; breakdown, implying the disintegration of the institution as a whole; and metamorphosis, "when foreign ministries around the globe would have an entirely new role with an entirely new logic of appropriateness informing the worldviews and identities of diplomats." 71 It is this last of these that would be relevant to the adoption of Options in conjunction with a character-related shift towards financial thinking in diplomacy. Arguably, because the world has become progressively embedded in financialized capitalism since the early 1970s, we have already seen the first movements towards this change, as diplomacy has correspondingly come to be driven by concerns relating to financial matters ${ }^{72}$-and, indeed, if Options could transform global capitalism, perhaps the most all-encompassing global institution of the modern era, then why can Options not transform the institutions of diplomacy and sovereignty? Bátora's typology of change suggests that diplomacy is mimetically formed, ${ }^{73}$ meaning that if one-ideally globally influential-sovereign state were to make a move towards an Options-based approach to

\footnotetext{
70 Bátora * "Does the European Union Transform the Institution of Diplomacy?," 50.

71 Bátora *, 51.

${ }^{72}$ Not to mention trade, culture, human rights, and so on. Cf. Bátora *, 53.

${ }^{73}$ Bátora *, 53.
} 
diplomacy, this may trigger the initiation of a new set of norms. For this reason, the next section addresses the United Kingdom's exit from the European Union.

\section{IV: Brexit: A Case Study in Options}

On June $23^{\text {rd }}, 2016$ the United Kingdom voted to leave the European Union (EU) by a margin of $48 \%$ to $52 \%$. The national referendum, a highly contentious affair, was only made more controversial by the close result. At the time, this event was seen as the culmination of 'Leave/Remain' campaign, yet four years later, the saga that has come to be known as 'Brexit' is still deep in the midst of negotiations with any number of uncertain outcomes remaining possible. After setting itself a list of twelve platitudinous principles, such as "providing certainty and clarity," 74 to guide Brexit proceedings, the British government saw draft versions of the withdrawal agreement rejected in the UK parliament no-less than three times over the course of a year before being finally ratified on $29^{\text {th }}$ January 2020 , this final act thereby initiating an exit transition period that is due to end $31^{\text {st }}$ December 2020. The clock is now ticking for the UK to strike deals not only with the EU on matters relating to trade, movement of people, borders, and numerous other issues, but also with non-EU countries with which it is hoping to replicate existing EU deals. ${ }^{75}$ If it cannot strike these deals, the UK will have to revert to WTO rules, which would be devastating for the UK economy. The task is steep: the EU has concluded some 37 free trade agreements, has 27 other provisional treaties in force, and is in negotiations for a further 22 FTAs, all of which the UK will have to renegotiate on a bilateral basis. ${ }^{76}$ Particular sectors impacted by Brexit include: automobiles (43\% of UK auto exports go to the EU, $83 \%$ of UK imports come from the EU), chemicals ( $60 \%$ of UK chemical exports go to the EU, $73 \%$ of UK imports are from the EU), financial services (London is the largest financial center in Europe, and this sector makes up a third of UK services exports), business services (39\% of these services go to the EU), and data

\footnotetext{
${ }^{74} \mathrm{Cf}$.

https://assets.publishing.service.gov.uk/government/uploads/system/uploads/attachment_data/file/589191/The_ United_Kingdoms_exit_from_and_partnership_with_the_EU_Web.pdf

${ }^{75}$ Shayerah Ilias Akhtar. 'Brexit and Outlook for U.S.-UK Free Trade Agreement' (CRS Report Number: IF11123)

Retrieved from Congressional Research Service website: https://crsreports.congress.gov/product/pdf/IF/IF11123/5

${ }^{76}$ Rudolf G. Adam, Brexit: Causes and Consequences (Cham: Springer International Publishing, 2020), 248,

https://doi.org/10.1007/978-3-030-22225-3.
} 
flows. ${ }^{77}$ It is excellence in thse key sectors that the UK is hoping will make it an appealing proposition to any new partners in international economic interaction. ${ }^{78}$

Despite the ostensible focus on matters relating to trade, Brexit is about much more than economics and has long been cast as a reclamation of UK sovereignty. ${ }^{79}$ Such a claim is not without foundation-scholars have long been describing the EU as a challenge to the basic principles of Westphalian sovereignty. ${ }^{80}$ However, for the UK's Leave voters, the EU is a kind of imperial supranational entity, sucking the UK dry of its wealth and autonomy. ${ }^{81}$ Leave voters do not care as much about having good trade deals after Brexit as they do about having a clean break from its institutional arrangements. In recent discussions, the UK's leading negotiator David Frost has been re-emphasizing that the UK is after a relationship in which the UK regains "sovereign control of our own law, border, and waters," in response to suggestions that Michael Barnier, the EU's negotiator, is seeking continuing arrangements very much like those held when the UK was a member of the EU. ${ }^{82}$ For many in the UK, they would rather see the UK adopt a damaging policy of isolationism.

As it happens, Britain has a history of isolationism with its so-called doctrine of 'splendid isolation.' This doctrine, held under the balance of power arrangements following from the Congress of Vienna in 1815, was based on the UK's belief that it stood to lose more than it might gain from alliances and that it was better off playing the role of protecting the balance's equilibrium. ${ }^{83}$ Still, relevant to our discussion, it is worth noting that the UK did-frequentlyenter itself into temporary relations with other nations during this period to deal with special

\footnotetext{
77 Derek E. Mix, Shayerah Ilias Akhtar, Kristin Archick. Brexit: Status and Outlook. CRS Report Number: R45944 (Washington, DC: Congressional Research Service, 2020) https://crsreports.congress.gov/product/pdf/R/R45944 78 cf. Walter Russell Mead. 'The Churchill Complex' Review: Anglo-American Attitudes'. The Wall Street Journal. Aug. 21, 2020. https://www.wsj.com/articles/the-churchill-complex-review-anglo-american-attitudes11598021811?mod=MorningEditorialReport\&mod=djemMER h. [Accessed August 22 2020.]

79 The 'Leave Campaign' was run with the slogan 'Take Back Control'. Cf. 'Brexit Britain's weakness exposed in US trade deal documents' The Conversation`. Mar. 12, 2019. https://theconversation.com/brexit-britains-weaknessexposed-in-us-trade-deal-documents-113077 [accessed Aug 25 2020]

${ }^{80}$ Bátora *, "Does the European Union Transform the Institution of Diplomacy?," 44.

${ }^{81} \mathrm{Cf}$. Meister, Justice Is an Option, 24.

82 Sam Fleming and Sebastian Payne. 'Michael Barnier accuses UK of wasting time in Brexit trade talks'. The Financial Times. Aug. 21, 2020 https://www.ft.com/content/f6c2ef12-56eb-4adc-afec$\underline{6363 e e 5 f d 379}$ ?emailld=5f47a392e0d17a0004bddfce\&segmentld=45d174cb-2a74-ff56-4de8b01cf042d140\&ftcamp=crm/email//nbe/Brexit/product [accessed Aug 22, 2020]

${ }^{83}$ Kissinger, Diplomacy, 97, 145, 157.
} 
circumstances. The stopping power of water (in conjunction with being perhaps the most significant sea power of the age), permitted it the privilege of picking and choosing its arrangements in a manner reminiscent of the Real Options approach, and it is perhaps the historical prestige that the UK has carried that has given it such confidence going into the abyss of Brexit-deal or no-deal. The issue is that surveys suggest that Brexit was and remains an emotive rather than a rational act for much of the UK public, ${ }^{84}$ and this weighs heavily on negotiators who are aware that any outcome will appear as a failure to a large proportion of the population. Diplomats, although familiar with projecting an uncompromising nationalism that they do not always personally feel, ${ }^{85}$ will in such a situation be hesitant and overly-cautious in steering the process forward, and would therefore greatly benefit from the possibilities offered by Options. A mutually acceptable solution is required, and by leaving open various options, formalized as Options, the UK may yet be able to benefit from future uncertainty and volatility. Britain will be like a young nation in the post-Brexit world, and it is established wisdom in corporate finance that young firms have higher returns than older more established firms. ${ }^{86}$

In assessing the opportunities and difficulties for Options diplomacy, it is useful to highlight some key issue areas emerging in the Brexit negotiations. Two issues that have become particularly thorny are fisheries and the so-called 'level playing field.' Speaking to the first issue, the UK has a vast competency in fisheries (and agriculture) and has a sovereign claim to waters rich in diverse sea-life. The EU currently has relatively unimpeded access to these waters but will lose this access if a Brexit deal cannot be reached and the exclusive rights to these waters are repatriated to the UK. Generating further difficulties, the majority of these competencies fall within the jurisdiction of Scotland and Wales, the former having little interest in a UK isolationist doctrine and hoping that it will, soon, be permitted the opportunity to have a second referendum for separation from the rest of the UK. ${ }^{87}$ Granting Scotland repatriated jurisdiction over a profitable and desirable fisheries industry would come with risks given Scotland's desire to exit the UK and re-enter the EU. In such a situation, it may be beneficial to consider how Puts and

\footnotetext{
${ }^{84}$ Brian M. Hughes, The Psychology of Brexit: From Psychodrama to Behavioural Science (Cham: Springer International Publishing, 2019), 40, https://doi.org/10.1007/978-3-030-29364-2.

${ }^{85}$ Watson, Diplomacy The Dialogue Between States, 101.

${ }^{86}$ Berk and DeMarzo, Corporate Finance, 838.

${ }^{87}$ Adam, Brexit, 214.
} 
Calls might help. 'Purchasing' a Put Option, for instance, could act as an insurance policy should the UK grant Scotland jurisdiction over fisheries and then later end up losing Scotland in a referendum. Conversely, 'selling' a Put to Scotland could feasibly appease them not having full repatriation for fear that they may succeed. On the flipside, the EU has a great interest in maintaining EU vessels' access in UK waters. The opportunity to enter into fixed term arrangements-potentially through Call Options-may be of appeal. Barnier has made it clear that losing access to UK waters would be "simply unacceptable" and may lead to "partial destruction of the EU fishing industry". ${ }^{88}$ The use of Call options could also pre-empt the finalization of Brexit negotiations and help to force the EU's hand in negotiations by opening up fisheries as the Option to non-EU countries for a higher exchange fee than would be offered to the EU. If another state was to take up the Call, the UK stands to benefit, if they do not, the EU still remains under pressure.

Despite worries over the fisheries industry, the EU remains more concerned about maintaining level-playing field standards in relation to state aid, labor and environmental protections, and taxation agreements. For the UK, the prospect of diverging from EU rules and regulations relating to such standards offers greater flexibility in its other trade negotiations and capitalizes on its considerable comparative advantage in key sectors. ${ }^{89}$ This conflict of interest naturally puts the two sides at an impasse because the EU has no interest in entering into a trade deal if the UK will then be able to compete with members of the EU's single market unfairly. The UK wants to pick and choose from the level-playing field demands. In the fashion of a traditional trade negotiation, it is offering to accept some tariffs in exchange for the EU relaxing its levelplaying field demands. ${ }^{90}$ Again, however, we see how a more innovative diplomatic approach employing Options could better mediate the interests of negotiating parties, each of whom have

\footnotetext{
${ }^{88}$ George Parker and Jim Brunsden. 'Michael Barner warns 'no progress' made on key issues in Brexit talks'. The Financial Times. Jul. 23, 2020. https://www.ft.com/content/14e6c44f-5573-46c1-8f4c224747562c42?emailld=5f1980d36bbc3300048376a2\&segmentld=45d174cb-2a74-ff56-4de8b01cf042d140\&ftcamp=crm/email//nbe/Brexit/product [accessed Aug. 22, 2020]

${ }^{89}$ Cf. Shayerah Ilias Akhtar. Brexit and Outlook for U.S.-UK Free Trade Agreement. CRS Report Number: IF11123. (Washington, DC: Congressional Research Service, 2020), https://crsreports.congress.gov/product/pdf/IF/IF11123/5

$90 \mathrm{Jim}$ Brunsden, Mehreen Khan and George Parker/ 'UK and EU look for compromises after Brexit talks end in stalemate'. The Financial Times. Jun. 5, 2020 https://www.ft.com/content/bf3df5c5-dee2-4071-b201-

32130111ce1c [accessed Aug. 22, 2020]
} 
their positive or negative assessment of the future value trajectory in particular areas. In this case, it may make sense to utilize a Real Options approach and the various Options allowing parties to enter, abandon, expand, or contract operations. These would be time-limited agreements that could break the deadlock while assuring both parties that they moved forwardin each case, the opposing sides would have to agree to Options that reflected their optimism or pessimism concerning their own value proposition in the trade relationship.

Putting aside the UK's negotiations with the EU, there external events and deals are still to be considered. Much of the UK's aspirations for profit in the post-Brexit world rely on the possibility of successfully negotiating a bilateral agreement with the US. The reality of the situation is, however, delicate. The Trump Administration has had great difficulty getting the renegotiated NAFTA agreement (USMCA) through US congress, suggesting that any hopes the UK might have for a quick US trade deal are unlikely. Unfortunately, the UK's Prime Minister Boris Johnson has vaunted this trade deal as the perfect way of offsetting the economic impact of leaving the EU. ${ }^{91}$ The UK is seemingly placing all of its eggs in one basket when it should be hedging its options. The problem is, as Walter Russell Mead has recently pointed out, ${ }^{92}$ the UK has not in the post-war period spent any of its efforts fostering close relationships with states other than the US and those in western Europe-fruitful partnerships with Canada, Australia, and New Zealand would significantly increase UK options in the present and yet have no strong foundation in recent history. Further compounding the issue is that the US knows how time pressured the UK is given the countdown to Brexit completion, and unless the UK can set up its options (or Options) in advance of a full deal being struck it will likely find itself being on the end of a deal that benefits the US far more than its new trade partner. ${ }^{93}$ The US has little interest in further adding to its trade surplus by importing from the UK's exceptionally strong service sector,

\footnotetext{
91 Julian Borger. 'We'll block trade deal if Brexit imperils open Irish border, say US politicians'. The Guardian. Jul. 31, 2019. https://www.theguardian.com/politics/2019/jul/31/brexit-mess-with-good-friday-and-well-block-uktrade-deal-us-politicians-warn [accessed Aug. 21. 2020]

92 cf. Walter Russell Mead. 'The Churchill Complex' Review: Anglo-American Attitudes'. The Wall Street Journal. Aug. 21, 2020. https://www.wsj.com/articles/the-churchill-complex-review-anglo-american-attitudes11598021811 ?mod=MorningEditorialReport\&mod=djemMER h. [Accessed August 22 2020.]

${ }_{93}$ Gaby Hinsliff. 'Of course the US supports a no deal - it makes a minnow out of Britain'. The Guardian. Aug. 13, 2019. https://www.theguardian.com/commentisfree/2019/aug/13/us-no-deal-john-bolton-trade-foreign-policy [accessed Aug 21, 2020]
} 
and will more likely have its eyes on exploiting the UK's health services market by pushing for privatization of sections of the National Health Service (NHS) ${ }^{94}$ This scenario comes straight out of the 1970s neoliberal playbook for 'structural adjustment plans,' and would constitute an example of the US exercising its own Options to benefit from Brexit.

Taking a step back from these specifics, it may be worth considering briefly what options remain on the table for the UK. In financial Options, the pricing models for specific propositions are often developed with mathematical models employing binomial trees; in Real Options these models are adapted into decision trees. The point, in either case, is to map out possible future scenarios and the different value propositions that will eventuate in each case. ${ }^{95}$ This mapping can be done for Brexit in broad terms. One option, for instance, is to have a second referendum. There is much justification for this because it would, in fact, give the UK public more options in deciding how they wish to remain in or depart from the UK. ${ }^{96}$ Another option, one already exercised multiple times, would be to request a longer time to expiration of the UK's membership in the EU single market and customs union. We can here consider how Options with longer times to expiration acquire greater value-they permit the owner of the Option more time to learn about the uncertainty and volatility facing them in decisions related to other investments. ${ }^{97}$ Nodeal remains an option, of course, though few would consider this an option bestowing much value for reasons outlined above. A more interesting, though perhaps unlikely, option would be for the UK to pursue its plans to enter into a 'Common Market 2.0,' otherwise known as the Norway plus option. It would mean the UK has a similar relation to the EU that Norway does, with the addition of a customs union, while departing from the EU's decision-making bureaucracy. While freedom of movement would continue-a highly contentious issue that may not fly for many Britons - the UK would, in effect, be able to benefit the institutional arrangements of having access to the EU while preserving the its sovereignty, and optionality. Enticingly, there are

\footnotetext{
94 'Brexit Britain's weakness exposed in US trade deal documents'. The Conversation. Mar. 12, 2019. https://theconversation.com/brexit-britains-weakness-exposed-in-us-trade-deal-documents-113077 [accessed August 20, 2020]

95 Berk and DeMarzo, Corporate Finance, 790.

${ }^{96}$ One of the continuous criticisms leveled at the 2016 referendum is that the binary choice of Leave or Remain completely ignored the complexity of the decision, and led to the present difficulties and divisions in UK and EU society. Cf. Adam, Brexit, 221.

${ }^{97} \mathrm{Li}$, "Real Options Theory and International Strategy," 73.
} 
no practical reasons why the EU would object to this plan. It has similar arrangements with other countries (such as Norway) - the difficulty will be in convincing UK citizens that maintaining a policy of freedom of movement enhances their options instead of diminishing them. ${ }^{98}$

\section{Conclusion}

The arguments presented in this paper are both speculative and theoretical. However, while the prospects for Options-based diplomacy may seem improbable, I maintain that they are possible. The reader would do well to note that revolutionary change in the operations of capitalism likely seemed unimaginable in the early nineteen-seventies, and yet that is just what happened. Today, capitalism cannot be separated from its financialized context, and much of what made this transformation possible can be attributed to technical innovations in the pricing of Options. ${ }^{99}$ Indeed, much of my argument rests on the claim that what may seem improbable or impossible is, in fact, simply the medium of contingency upon which the future rests, and that it is through Options that we may prosper under the conditions of such radical uncertainty.

My claims concerning the medium of contingency, the primacy of diplomatic practice over strategic theory, the optionality embedded in sovereignty, and the usefulness of Real Options for matters of international politics, have all served to demonstrate that value, however it is conceptualized, is inextricably linked to the quality of optionality. Repeating myself once more: the one thing we know about the future is that it will not be identical to the past. In an uncertain world that presents many opportunities for lose-lose or zero-sum situations, the appeal of using Options to generate win-win outcomes should be enough to foster interest in producing more research into the conceptual framework outlined above. I consider my work the starting point to a broader-and likely more technical/less theoretical-discussion about the possibilities, opportunities and threats to an Options-based diplomacy. This facility would not replace

\footnotetext{
98 In this scenario the UK would not longer be subject to eth Common Agricultural or Fisheries Policies. Cf. James Randerson and Hanne Cokelaere. 'UK's Brexit options - an illustrated guide'.' Politico Mar 30, $2019 .$. https://www.politico.eu/article/uks-brexit-options-explained/ [accessed Aug 20, 2020]

${ }^{99}$ The now-famous Black-Scholes Options Pricing Formula originally and inconspicuously presented in: Black and Scholes, "The Pricing of Options and Corporate Liabilities."
} 
traditional diplomacy or international strategic planning; it would merely add one more dynamic element to existing practices. So to those skeptical of my claims, I would say: perhaps, for now, we could do worse than at least consider the Option.

\section{BIBLIOGRAPHY}

Adam, Rudolf G. Brexit: Causes and Consequences. Cham: Springer International Publishing, 2020. https://doi.org/10.1007/978-3-030-22225-3.

Aglietta, Michel. Money: 5,000 Years of Debt and Power. London ; New York: Verso, 2018.

Akhtar, Shayerah Ilias. Brexit and Outlook for U.S.-UK Free Trade Agreement. CRS Report Number: IF11123. (Washington, DC: Congressional Research Service, 2020), https://crsreports.congress.gov/product/pdf/IF/IF11123/5

Ayache, Elie. "In the Middle of the Event." In The Medium of Contingency, edited by Robin Mackay. Urbanomic. MIT Press, 2011.

Bátora *, Jozef. "Does the European Union Transform the Institution of Diplomacy?" Journal of European Public Policy 12, no. 1 (February 2005): 44-66. https://doi.org/10.1080/1350176042000311907.

Berk, Jonathan B., and Peter M. DeMarzo. Corporate Finance. 4th edition. Boston: Pearson, 2017.

Berridge, G. R. Diplomacy. London: Palgrave Macmillan UK, 2015. https://doi.org/10.1057/9781137445520.

Black, Fischer, and Myron Scholes. "The Pricing of Options and Corporate Liabilities." The Journal of Political Economy 81, no. 3 (1973): 637-54.

Bodie, Zvi, Alex Kane, and Alan J. Marcus. Essentials of Investments. Tenth edition. New York: McGraw-Hill Education, 2017.

Borger, Julian. 'We'll block trade deal if Brexit imperils open Irish border, say US politicians'. The Guardian. Jul. 31, 2019. https://www.theguardian.com/politics/2019/jul/31/brexitmess-with-good-friday-and-well-block-uk-trade-deal-us-politicians-warn [accessed Aug. 21. 2020]

Bremmer, Ian, and Preston Keat. The Fat Tail: The Power of Political Knowledge in an Uncertain World. Oxford ; New York: Oxford University Press, 2010.

Brunsden, Jim., Mehreen Khan and George Parker/ 'UK and EU look for compromises after Brexit talks end in stalemate'. The Financial Times. Jun. 5, 2020 https://www.ft.com/content/bf3df5c5-dee2-4071-b201-32130111ce1c [accessed Aug. 22, 2020]

Chi, Tailan, and Edward Levitas. "An Examination of Options Embedded in a Firm's Patents: The Value of Dispersion in Citations." In Real Options in Theory and Practice, edited by Jeffrey J. Reuer and Tony W. Tong. Financial Management Association Survey and Synthesis Series. Oxford ; New York: Oxford University Press, 2009.

Fleming, Sam., and Sebastian Payne. 'Michael Barnier accuses UK of wasting time in Brexit trade talks'. The Financial Times. Aug. 21, 2020 https://www.ft.com/content/f6c2ef12-56eb- 
4adc-afec-6363ee5fd379?emailld=5f47a392e0d17a0004bddfce\&segmentld=45d174cb2a74-ff56-4de8-b01cf042d140\&ftcamp=crm/email//nbe/Brexit/product [accessed Aug $22,2020]$

Freedman, Lawrence. Strategy: A History. New York: Oxford University Press, 2013.

Graeber, David. Debt: The First 5000 Years. Brooklyn, NY: Melville House, n.d.

Hamilton, Keith, and Richard Langhorne. The Practice of Diplomacy: Its Evolution, Theory, and Administration. 2nd ed. London ; New York: Routledge, 2011.

Hinsliff, Gaby. 'Of course the US supports a no deal - it makes a minnow out of Britain'. The Guardian. Aug. 13, 2019.

https://www.theguardian.com/commentisfree/2019/aug/13/us-no-deal-john-boltontrade-foreign-policy [accessed Aug 21, 2020]

Hughes, Brian M. The Psychology of Brexit: From Psychodrama to Behavioural Science. Cham: Springer International Publishing, 2019. https://doi.org/10.1007/978-3-030-29364-2.

Jönsson, Christer, and Martin Hall. Essence of Diplomacy. London: Palgrave Macmillan UK, 2005. https://doi.org/10.1057/9780230511040.

Kissinger, Henry. Diplomacy. New York: Simon and Schuster, 1994.

Li, Jing. "Real Options Theory and International Strategy." In Real Options in Theory and Practice, edited by Jeffrey J. Reuer and Tony W. Tong. Financial Management Association Survey and Synthesis Series. Oxford ; New York: Oxford University Press, 2009.

Maçães, Bruno. Belt and Road: A Chinese World Order. London: Hurst \& Company, 2018.

Marx, Karl. Capital: A Critique of Political Economy: Volume One. Translated by Ben Fowkes. Penguin Books, 1976.

Mead, Walter Russel., 'The Churchill Complex' Review: Anglo-American Attitudes'. The Wall Street Journal. Aug. 21, 2020. https://www.wsj.com/articles/the-churchill-complexreview-anglo-american-attitudes11598021811 ?mod=MorningEditorialReport\&mod=djemMER h. [Accessed August 22 2020.]

Meister, Robert. Justice Is an Option: A Democratic Theory of Finance for the Twenty-First Century. University of Chicago Press, 2021.

Mix, Derek E., and Shayerah Ilias Akhtar, Kristin Archick. Brexit: Status and Outlook. CRS Report Number: R45944 (Washington, DC: Congressional Research Service, 2020) https://crsreports.congress.gov/product/pdf/R/R45944

Otte, T.G. "Kissinger." In Diplomatic Theory from Machiavelli to Kissinger. Wiltshire, Great Britain: Palgrave, 2001.

Parker, George., and Jim Brunsden. 'Michael Barner warns 'no progress' made on key issues in Brexit talks'. The Financial Times. Jul. 23, 2020. https://www.ft.com/content/14e6c44f5573-46c1-8f4c-

224747562c42?emailld=5f1980d36bbc3300048376a2\&segmentld=45d174cb-2a74ff56-4de8-b01cf042d140\&ftcamp=crm/email//nbe/Brexit/product [accessed Aug. 22, 2020]

Randerson, James., and Hanne Cokelaere. 'UK's Brexit options - an illustrated guide'. Politico Mar 30, 2019.. 
Reuer, Jeffrey J., and Tony W. Tong, eds. Real Options Theory. 1st ed. Advances in Strategic Management, 24.2007. Amsterdam: Elsevier JAI, 2007.

Satow, Ernest Mason. Satow's Guide to Diplomatic Practice. 5th ed. London ; New York: Longman, 1979.

Sharp, Paul. "Diplomatic Theory of International Relations," n.d., 359.

Stigum, Marcia L., Anthony Crescenzi, and Marcia L. Stigum. Stigum's Money Market. 4th ed. New York: McGraw-Hill, 2007.

Taleb, Nassim Nicholas. The Black Swan: The Impact of the Highly Improbable. New York: Random House, 2010.

Watson, Adam. Diplomacy The Dialogue Between States. Florence: Taylor and Francis, 2013. [Unknown] 'Brexit Britain's weakness exposed in US trade deal documents'. The Conversation. Mar. 12, 2019. https://theconversation.com/brexit-britains-weakness-exposed-in-ustrade-deal-documents-113077 [accessed August 20, 2020] 